\title{
Práticas avaliativas nos cursos de pedagogia: concepções, modelos e planejamento
}

\author{
Evaluation practices in pedagogy courses: concepts, models and planning
}

\author{
Maria de Lourdes da Silva Neta \\ e-mail: lourdes.neta@ifce.edu.br \\ Instituto Federal de Educação, Ciência e Tecnologia do Ceará-IFCE. Brasil
}

\author{
Antônio Germano Magalhães Junior iD \\ e-mail: germano.junior@uece.br \\ Universidade Estadual do Ceará-UECE. Brasil
}

Maria Terla Silva Carneiro do Santos

e-mail: terlasilvacs@gmail.com

Universidade Estadual do Ceará-UECE. Brasil

\begin{abstract}
Resumo
As práticas avaliativas estão inseridas no trabalho docente em todos os níveis e modalidades da educação podendo auxiliar no direcionamento dos processos de formação, na emissão do juízo de valor e na tomada de decisão por gestores e professores. O objeto da pesquisa aportou-se nas práticas de avaliação disseminadas nos cursos de licenciatura em Pedagogia de uma IES pública cearense. Objetivamos compreender as práticas avaliativas dos docentes. Os aspectos teóricos e metodológicos tiveram por base os escritos de Luckesi (2011), Roldão e Ferro (2015), Sordi e Ludke (2012), dentre outros. A metodologia de cunho qualitativo recorreu à postura cartográfica utilizando técnicas de coleta de dados bibliográfica, documental e entrevistas por pautas com professores. As práticas se constituíram pelas concepções de medida, instrumento e controle. Evidenciamos que as práticas avaliativas no ensino-aprendizagem pautadas no planejamento e nos modelos avaliativos no âmbito da educação superior nos levaram a constatar a relevância e necessidade de aquisição do conhecimento em avaliação pelos docentes, requerendo articulações com as concepções de currículo, uma vez que nelas se expressam, sobretudo as escolhas dos conteúdos, as definições emanadas do planejamento, a adoção dos modelos, a sistematização dos instrumentos e critérios com escopo no trabalho do professor e na aprendizagem dos discentes.
\end{abstract}

Palavras chave: práticas de avaliação; formação de professores; pedagogia; ensino superior.

\section{Abstract}

Evaluative practices are inserted in the teaching work at all levels and modalities of education and can assist in directing the training processes, in issuing value judgments, and in decision making by managers and professors. The object of the research was based on the evaluation practices disseminated in undergraduate courses in Pedagogy of a public High Education Institution in Ceará. We aim to understand the evaluative practices of educators. The theoretical and methodological aspects were based on the writings of Luckesi (2011), Roldão and Ferro (2015), Sordi, and Ludke (2012), among others. The qualitative methodology used the cartographic posture using techniques of bibliographic and documentary data collection, and interviews with guidelines with professors. The practices were constituted by the conceptions of measure, instrument, and control. We highlight that the evaluative practices in teaching-learning based on the planning and evaluation models in the context of higher education led us to see the relevance and need for the acquisition of knowledge in evaluation by educators, requiring articulations with the curriculum concepts, since in them the content choices, the definitions originating from the planning, the adoption of the models, the systematization of the instruments and criteria with scope in the work of professors and the learning of students are expressed above all.

Keywords: assessment practices; training of teachers; pedagogy; higher education.

Recibido / Received: 27-12-2020

Aceptado / Accepted: 03-04-2021

Publicación en linea / Published online: 28-07-2021

Cómo referenciar este artículo / How to reference this article:

da Silva Neta, M. L., Junior, A. G. M., \& Carneiro do Santos, M. T. S. (2021). Práticas avaliativas nos cursos de pedagogia: concepções, modelos e planejamento. Tendencias Pedagógicas, 38, pp. 137-147. doi: 10.15366.tp2021.38.012. 


\section{Introdução}

As investigações versando acerca da temática avaliativa, principalmente a partir dos anos de 1990 estão presentes nos diversos níveis e modalidades que constituem o cenário educacional brasileiro, bem como, nos estudos internacionais. Pesquisam-se e divulgam informações sobre as políticas de avaliação interligadas as avaliações externas, assim como, buscam-se compreender os aspectos vinculados a aprendizagem dos estudantes nas instituições de ensino aliado ao trabalho formativo realizado pelos professores.

Evidenciamos que algumas produções científicas trazem à baila a avaliação da aprendizagem como área de conhecimento da avaliação educacional desenvolvendo-se tanto no contexto nacional quanto internacional, considerando-a como componente indissociável do processo ensino e aprendizagem, sendo elemento fundante do currículo, dos sistemas de ensino e das políticas educacionais.

Pensar sobre o papel que a avaliação da aprendizagem cumpre na educação escolar nos remete à discussão sobre as especificidades do trabalho do professor e as implicações que constituem os conhecimentos pedagógicos da ação docente, o planejamento, a organização didática, as metodologias.

Pelo fato da avaliação gerar informações acerca da aprendizagem, podendo auxiliar na tomada de decisões dos professores para o redimensionamento das ações formativas, norteamos a pesquisa em voga partindo das seguintes indagações: Que práticas avaliativas foram utilizadas na formação dos licenciados em Pedagogia? Como foi realizado o planejamento das avaliações nos Cursos de Pedagogia? Quais as concepções e os modelos de avaliação adotadas para constituírem as práticas avaliativas nas licenciaturas em Pedagogia?

A partir dos questionamentos a pesquisa objetivou compreender as práticas de avaliação disseminadas nos cursos de licenciatura em Pedagogia, de modo específico nas disciplinas de Didática Geral e Avaliação.

O estudo emana de inquietações advindas de nossas pesquisas em que constatamos que a avaliação da aprendizagem realizada no ensino superior, é comumente empregada como mero instrumento de verificação do conhecimento acumulado pelo estudante no decorrer do semestre, pautada na aplicação de instrumentais.

Silva Neta (2018) enfoca que o conhecimento avaliativo dos professores pode tornar o processo de avaliação do ensino e da aprendizagem, um importante subsídio destinado ao direcionamento das ações formativas na Educação Básica e Superior, possibilitando melhorias no planejamento, no ensino, na adoção das estratégias metodológicas pelo professor, levando-nos a concordar com a premissa de que o conhecimento avaliativo docente se constitui, de forma particular, através da formação, saberes e práticas de ensino, o que justifica nosso interesse em conhecer práticas avaliativas na formação docente em Pedagogia.

Destarte, nesse escrito conceituamos na primeira seção a avaliação mediante os conceitos organizados por estudiosos do tema; seguimos com a descrição do percurso metodológico e finalizamos com as práticas avaliativas na docência universitária, de modo específico nos Cursos de Pedagogia.

\section{Avaliação: conhecendo os aspectos conceituais}

$\mathrm{Na}$ área da Educação, a avaliação existe em vários âmbitos: em larga escala, institucional, curricular, do ensino e aprendizagem, dentre outras. A temática da avaliação, em seus diversos aspectos, é pesquisada em diferentes cursos de graduação e Pós-Graduação no Brasil e em outros Países, sendo temática que possibilita a compreensão dos aspectos didáticos aliados à tomada de decisão dos docentes referentes ao ensino e destinando-se à aprendizagem dos estudantes na Educação Básica e Superior, assim como, os dados coletados possibilitam aos docentes reflexões acerca do trabalho formativo em determinado período, atentando para as aprendizagens, desafios na perspectiva de que sejam utilizadas estratégias metodológicas que gerem melhorias no ensino, sanem as dificuldades e proporcionem conhecimentos.

Ao professor, é necessário conhecer a avaliação e seus significados, na perspectiva de utilizá-la na organização do planejamento avaliativo, na definição da concepção, na escolha do modelo, na seleção da técnica e tipo, auxiliando no planejamento e na elaboração dos instrumentos, na seleção dos critérios avaliativos, na fundamentação de feedbacks e nas decisões para sanar as dificuldades de 
aprendizagem em face aos conteúdos ensinados.

A escolha da avaliação - como objeto central da ação formativa - de modo específico em nossa pesquisa, versando sobre a formação de professores, deve-se à reconhecida importância que tem como um elemento estruturante do processo de ensino-aprendizagem e intrínseco ao trabalho docente em níveis e modalidades distintas. A diversidade das práticas avaliativas existentes nas instituições de formação quer entre cursos ou departamentos; quer entre professores, implica um trabalho organizacional no sentido de procurar pontos de entendimento e a definição de procedimentos que permitam processos de aferição, de diagnóstico, de tomada de decisões e, principalmente de análise acerca dos avanços e entraves que necessitam serem superados pelos estudantes e orientados pelos professores.

Salientamos que por trás das práticas avaliativas existem múltiplas interpretações e divergências, baseadas tanto em diferenças conceptuais, como na forma como é entendida a concretização dessa avaliação. Essas diferenças, provenientes de diferentes pontos de partida, condicionam as possibilidades de modificação da proposta de ensino, transpondo as dificuldades de compreensão dos aspectos da avaliação entre professores (Roldão \& Ferro, 2015).

Sendo assim, aclaramos que o processo avaliativo consiste na obtenção de informações pautadas na aplicação de instrumentos válidos e confiáveis gerando segurança nos resultados e fomentando o juízo de valor com o intuito de promover a tomada de decisões que solucionem as dificuldades encontradas no decorrer do processo formativo. Avaliar envolve necessariamente, uma ação que promova a melhoria do processo de ensino e aprendizagem, o que aponta para uma concepção diferenciada de fazer ensino e aprendizagem. Do ponto de vista de Luckesi (2011, p. 174), a avaliação deve ser de acompanhamento, porque «investiga a qualidade dos resultados em andamento sucessivamente, primeiro sob o foco formativo - processo - e, segundo, sob o foco final de uma ação - produto», ou seja, proporciona a investigação de todo o processo de construção do conhecimento, realizando investimentos para que o resultado seja satisfatório, ou melhor, para que aprendizagem ocorra.

Para ser uma ação pedagógica, a avaliação deveria ser vista como uma investigação do conhecimento que possibilita a intervenção para a melhoria do resultado do ensino, ainda em construção, dando suporte ao professor. Portanto, a avaliação formativa envolve duas componentes: avaliação para a aprendizagem (professor) e avaliação como aprendizagem (aluno) quando utilizam as informações do feedback do processo ensino e aprendizagem para análise e tomada de decisões. Avaliação é uma leitura orientada da realidade, ou seja, um construto que precisa de planejamento, objetivos, modelos, critérios, instrumentos, feedback que serva para os professores na perspectiva norteadora que constituem as ações do trabalho docente e aos estudantes como orientadora das aprendizagens.

O conceito de avaliação do ensino-aprendizagem informado por Luckesi (2011, pp. 92-93) como «ação formulada a partir das determinações da conduta de atribuir um valor ou qualidade a alguma coisa, ato ou curso de ação, que, por si, implica um posicionamento positivo ou negativo em relação ao objeto, ato ou curso de ação avaliado [...]», aborda o ato de avaliar, que implica coleta, análise e síntese dos dados conduzindo a tomada de decisões, aspectos que constituem o objeto da avaliação, acrescido de uma contribuição de valor ou qualidade. Cabe então ao professor, conhecer a aprendizagem dos discentes tendo ciência das dificuldades para que possa redimensionar o ensino de acordo com as exigências formativas do curso de graduação atentando para o desenvolvimento do perfil profissiográfico dos estudantes, propondo estratégias provocadoras de conhecimento.

A avaliação pode promover a constituição do conhecimento dos estudantes com os ensinamentos ensejados pelos docentes na intencionalidade de promoção de reflexão, para que estes fundamentos educacionais sejam ampliados e sistematizados para situações diferenciadas com possibilidades de aplicabilidade no contexto em que o discente está inserido.

Silva Neta \& Magalhães Junior evidenciaram a necessidade do professor utilizar a avaliação:

Ao professor é imprescindível valer-se da avaliação como recurso a serviço do ensino e aprendizagem, utilizando-a nos momentos formativos, uma vez que qualquer atividade habitual de aprendizagem pode e deve ser avaliada; por exemplo, um estudo de texto, uma aula de campo, uma pesquisa proposta, desde que essas atividades sejam sustentadas por objetivos e critérios definidos previamente e informados aos discentes [...]. (Silva Neta \& Magalhães Junior, 2017, p. 40) 
Os aspectos processuais da avaliação podem ser levados em consideração, principalmente pelos professores, uma vez que, é relevante para a aprendizagem dos estudantes e para o ensino, pelo fato de indicar os aspectos de revisão de programas, redimensionamento de conteúdos e práticas, propõe questionamentos, demonstrando incompletudes e indicando caminhos. Deve permanecer retroalimentando o processo, privando de reduzir-se a um momento final de aplicação dos instrumentos quando se encontra uma nota ou conceito para ranquear os que sabem dos que deixaram de aprender sem ações que possam sanar as dificuldades.

Nos escritos de Sordi e Ludke (2009, p. 314), avaliação da aprendizagem foi evidenciada como « [...] uma categoria constitutiva do trabalho pedagógico com alta força indutora nas formas de agir dos atores escolares merecendo atenção especial visando entender/desvelar seu modus operandi, dentro e fora da sala de aula, dentro e fora das instituições formativas». Como dimensão constituinte do trabalho pedagógico, cabe ao docente compreender os padrões estabelecidos para as etapas formativas e refletir para agir ante as informações encontradas, ou seja, que decisões serão tomadas para induzir a aprendizagem dos estudantes e atender as demandas institucionais e sociais nas quais estão inseridos os discentes e docentes.

Sendo a avaliação do ensino e da aprendizagem elemento do ato pedagógico, é um componente essencial de todo o processo educacional. Por isso, é preciso evitar que seja praticada de forma isolada e seletiva. Avaliar requer uma busca de soluções que estejam presentes à realidade educacional, variantes e condicionantes políticos, econômicos, sociais e culturais que interferem no processo ensino - avaliação - aprendizagem.

Asseveramos que a avaliação do ensino e aprendizagem precisa existir com intenção de conhecer as aprendizagens dos discentes e o que falta aprender, para que o docente providencie os meios de aprendizagem e desenvolva um trabalho que contribua nos estudos. A avaliação necessita ser percebida como aliada do professor, evitando-se resumir a atribuição de nota, conceito ou menção baseada na concepção de controle ou medida. Avalia-se, por conseguinte, para promover e auxiliar na aprendizagem dos estudantes. Sendo assim, destacamos que existe um conhecimento específico na área de avaliação, de sorte que, é necessário o docente possuí-lo para auxiliar na tomada de decisão no decorrer do trabalho formativo realizado nos cursos de licenciatura, especificamente nos de Pedagogia.

Posterior às dimensões conceituais destinadas a avaliação, no item a seguir evidenciamos o percurso metodológico percorrido na investigação.

\section{Percurso metodológico: caminhos trilhados na investigação}

O percurso metodológico recorreu à abordagem de pesquisa qualitativa orientada pela interpretação da realidade, considerando o homem como sujeito que produz significados, vulnerável à própria subjetividade e que constrói, portanto, verdades relativas. Sendo assim, na referida abordagem, a investigação é entendida como «extensão do pesquisador, que é portador de interesses e valores que interferem nas suas opções» (Prado \& Cunha, 2007, p. 21).

Para interpretarmos a realidade, ou melhor, as realidades pesquisadas, escolhemos como postura investigativa a cartografia como orientadora de percurso colocando o pesquisador imerso no processo, não somente como executor da ação de pesquisar, mas como um ente que apresenta suas percepções e sensações vividas no encontro com seu campo e objeto de estudo. A relação do pesquisador com o campo de pesquisa não se constitui como espaço de neutralidade, mesmo sabendo que devemos cuidar em não «conduzirmos» a pesquisa para os caminhos que acreditamos serem os melhores e mais corretos em relação aos seus resultados. Muitos pesquisadores iniciam suas investigações procurando confirmar suas «verdades», proporcionando a manutenção do que acreditam ser a explicação para o entendimento do real, não ficando somente em análises teoréticas. Quando descrevemos nossos percursos, escolhas, dúvidas, na verdade tudo que sentimos e fazemos nas nossas «trilhas» da pesquisa, estamos possibilitando uma atenção a princípios de fidelidade com a realidade, procurando demonstrar o que sentimos, mas não podendo alterar os resultados encontrados com o objetivo de satisfazer nossas «verdades».

Alinhamos à pesquisa qualitativa à postura cartográfica na intenção de localizarmos os dados, utilizando às técnicas de pesquisa bibliográfica, documental e empírica na qual, dentre as fontes de pesquisa documental incluímos sete Projetos Pedagógicos de Curso (PPC) dos cursos de Pedagogia de uma Instituição de Ensino Superior (IES) pública cearense. Além dos projetos recorremos aos 
programas de ensino das disciplinas para identificarmos, nos ementários, os aspectos referentes à avaliação. Desta ação, localizamos 12 disciplinas, das quais, escolhemos as que apresentaram, em suas ementas, avaliação do ensino e/ou aprendizagem. Após essa segunda seleção, encontramos nove componentes curriculares, especificamente as disciplinas de Didática Geral e Avaliação. Além dos PPC e dos programas nos detemos em pesquisar no Regimento da Universidade as indicações referentes à avaliação.

Para a coleta dos dados empíricos convidamos os noves docentes que ministravam as disciplinas citadas anteriormente, realizando as entrevistas com oito docentes, uma vez que um dos professores ministrava Didática Geral e Avaliação no curso. As entrevistas foram realizadas por pauta, organizadas em uma categoria geral que eram as práticas de avaliação e, em três categorias especificas: concepções, planejamento e modelos avaliativos.

A partir da busca documental geradora da definição do perfil dos sujeitos realizamos o contato com as coordenações dos cursos a fim de conseguirmos informações especificas acerca dos docentes, bem como os números de telefone e os endereços de e-mails. É válido ressaltar a receptividade dos Coordenadores dos cursos, que forneceram os contatos telefônicos, ou melhor, o aplicativo Whats $A p p$ e endereços de e-mails dos docentes. Nesse trecho da pesquisa, a partir das informações reveladas pelos gestores, descobrimos que oito docentes tinham o perfil para participação no estudo.

Com a definição do quantitativo de sujeitos e os contatos em mãos, iniciamos o processo de convite para participação na pesquisa, explicando o objetivo da investigação, e de forma unânime os oito docentes propuseram-se a participar. Com o aceite, iniciamos o agendamento das entrevistas que foram gravadas em vídeo, transcritas na íntegra e, validada pelos participantes.

O grupo de docentes participantes da investigação possuíam as seguintes características: no tocante a formação inicial acadêmica, todos eram licenciados - sete com formação inicial em Pedagogia, sendo que um dos entrevistados possuía licenciatura em Ciências Biológicas e o oitavo em Geografia. No âmbito da formação em nível de Pós-Graduação quatro eram doutores na área de Educação, um em Geografia, dois mestres, sendo um na área de Educação, outro no Ensino de Geografia e um especialista em Educação. Em relação ao vínculo institucional tínhamos docentes efetivos e substitutos, sendo seis efetivos e dois substitutos. O tempo de experiência profissional no ensino superior variou de um ano e meio aos 29 anos. Atentando para os aspectos éticos da investigação evitamos revelar o nome da IES e na explanação das respostas dos sujeitos utilizaremos a palavra professor precedida de numeral.

Após apresentação da metodologia no item seguinte aclaramos os achados de pesquisa referente às práticas de avaliação disseminadas pelos docentes nos cursos de licenciatura em Pedagogia.

\section{Práticas de avaliação nos Cursos de Pedagogia: concepções, modelos e planejamento}

O ato de avaliar necessita de organização, investigação, diagnóstico, reflexão, compreensão acerca da realidade e, principalmente das ações posteriores à verificação, para que avaliação atinja sua finalidade de possibilitar ao professor e ao estudante, conhecer as situações de aprendizagem e promover decisões a respeito das ações de melhoria para que as dificuldades em relação aos conteúdos sejam sanadas. Diante dessa premissa, o planejamento avaliativo auxilia na organização, no alcance das finalidades e na compreensão da realidade fomentando a tomada de decisões constituintes da avaliação.

O docente que deixa de se dedicar à organização de sua ação pedagógica, consequentemente, o desenvolvimento do seu trabalho formativo fica fadado às condições esporádicas; decisões imediatas condicionadas ao acaso deixam de contribuir para alcançar as finalidades de formação. O planejamento é imprescindível para o direcionamento da prática pedagógica (Oliveira \& Damis, 2011).

A análise documental da pesquisa baseou-se em categorias, sendo a primeira categoria a avaliação. Partimos para a busca nos sumários dos sete PPC, ao qual descobrimos que um (01) deixou de sinalizar o plano de avaliação no índice; (02) dois PPC identificaram plano de avaliação e, (04) quatro planos de avaliação enfatizaram as dimensões externas, internas e aprendizagem. Com os achados iniciais extraídos dos sumários fomos para análise documental com a segunda categoria - avaliação do ensino e aprendizagem e não localizamos a referida categorização. Desse modo, escolhemos outra categoria - avaliação da aprendizagem para buscarmos as concepções avaliativas nos PPC.

A demarcação espacial de vigência dos PPC de mesmo curso ofertado pela IES era diferente, 
sendo dois (02) PPC datados de 2008, dois (02) de 2011, um (01) de 2013 e outros dois (02) de 2014. Asseveramos que todos os projetos atentaram para as indicações das DCN destinadas ao Curso de Pedagogia.

Nos PPC dos cursos datados de 2008 constavam as mesmas indicações para a avaliação que seria desenvolvida a partir de três instâncias básicas: externa, interna e aprendizagem. A concepção da avaliação como medida foi encontrada nos projetos dos cursos, sendo pautada no rendimento dos estudantes em que os docentes têm autonomia para criar as formas de avaliação das disciplinas que ministram podendo negociar com os estudantes as formas de avaliação.

A descoberta de que as indicações avaliativas contida nos sete projetos aportaram-se no regimento geral da Universidade, nos incentivou a sua procura, em que acessamos a internet, colocamos a nomenclatura do documento e baixamos o texto. Fomos à busca do capítulo que referenciava a avaliação e o localizamos com o título de avaliação do rendimento escolar. No capítulo $\mathrm{V}$ do regimento da IES a avaliação foi intitulada de avaliação do rendimento escolar, sem localizarmos a categoria avaliação da aprendizagem, ou seja, encontramos outra categorização denominada de avaliação da eficiência. No artigo 111 localizamos três concepções: medida, instrumento e controle. A concepção de medida mediante a verificação dos conhecimentos com demarcação temporal estabelecida para o período letivo da disciplina com atribuição de nota de 0,0 (zero) a 10,0 (dez); a concepção de instrumento, uma vez que explicita alguns tipos de instrumentais avaliativos em que os professores possuem autonomia de julgamento e liberdade na formulação e valoração de questões, assim como na fixação de tempo de duração das avaliações e de prazo para entrega de trabalhos desde que atentem para o calendário acadêmico da instituição; e, a concepção de controle, quando exige o exame após a finalização do período letivo e cumprimento do programa da disciplina.

A concepção de processo, no regimento da Universidade, deixou de ser evidenciada pela ausência das especificações concernentes a emissão do juízo de valor, por deixar de citar a tomada de decisão do professor perante as dificuldades demonstradas pelos estudantes no decorrer da formação.

Por termos encontrado similitude em relação aos aspectos da avaliação do ensino aprendizagem, em seis PPC de cursos de Pedagogia, decidimos analisar o regimento da Universidade no qual contatamos que avaliação foi tratada como verificação das aprendizagens finalizando com os aspectos quantitativos, mediante a finalização dos programas disciplinares pautados na aplicação dos instrumentos e atribuição de notas. Portanto, diferenciando do parecer do Conselho Nacional de Educação (CNE/CP) no 2/2015, uma vez que o Regimento instituiu a avaliação da eficiência antes da publicação dos referidos documentos.

Nos trechos da pesquisa documental a concepção de avaliação como processo foi aclarada em dois, dos sete PPC analisados, os demais se desvincularam dessa concepção, uma vez que tomaram por base as indicações do Regimento Institucional, na qual a avaliação será finalizada com término do programa da disciplina aliada a aplicação de instrumentos, chegando à quantificação das aprendizagens aclarando as concepções de medida, instrumento e controle.

A avaliação processual denota no acompanhamento do discente no decorrer do processo formativo, partindo do diagnóstico para identificar os conhecimentos prévios e a aprendizagem em busca do reconhecimento dos avanços e dificuldades, atentando para a divulgação dos critérios em prol da análise dos instrumentos utilizados pelo docente no transcorrer do percurso de formação.

Diante desse pressuposto de que avaliação processual necessita ser realizada para a mediação da aprendizagem dos discentes, buscamos compreender, nas entrevistas, o acompanhamento realizado pelos professores a partir do planejamento avaliativo das disciplinas de Didática e Avaliação vinculadas aos aspectos descritos nos PPC dos cursos.

Em relação ao planejamento avaliativo das disciplinas de Didática e Avaliação quatro docentes revelaram que recorriam aos ementários das disciplinas explícitos nos projetos dos cursos para organizar o planejamento das ações desenvolvidas no componente curricular, assim como para a elaboração do programa e definir as dimensões avaliativas. Conforme podemos conferir em uma das explanações «Assim como essa dimensão avaliativa do nosso projeto pedagógico do curso é processual, então o men planejamento é muito a partir do projeto pedagógico do curso» (PROFESSOR 02). $\mathrm{Na}$ fala constamos que avaliação processual foi sendo desenvolvida a partir das indicações contidas no PPC. Outro sujeito mencionou algo semelhante enfocando a historicidade e as características da turma. Um professor reportou seguir o ementário descrito no projeto de curso e que para organizar o programa da disci- 
plina Avaliação Educacional conversava com a professora que ministrou a disciplina de Didática pelo fato das ementas das duas disciplinas contemplarem a avaliação da aprendizagem revelando a importância de planejar junto com outros docentes e da relevância do cumprimento de todo programa organizado para o componente curricular.

Ainda tratando do planejamento avaliativo das disciplinas e vinculação com os aspectos no PPC quatro entrevistados informaram que recorrem aos projetos de curso, principalmente aos ementários, apesar das dificuldades para vincular os aspectos descritos nos projetos com a elaboração dos programas de disciplinas, um dos relatos denunciou a desatualização dos ementários e a necessidade de adaptação por parte do docente seja nos cursos de graduação ou de pós-graduação. Ainda mencionando descompassos, o professor 05 informou que «atualização do projeto foi ponto de pauta na reunião do Colegiado, uma vez, que consta no PPC que avaliação é continua, mas que nem sempre acontece por variar de acordo com a compreensão de cada professon.

A partir das considerações e dificuldades descritas pelos sujeitos em relação ao planejamento avaliativo e a relação com os PPC, analisamos os programas dos componentes curriculares no intento de compreendermos a sistematização dos planejamentos avaliativos. Ao agendarmos as entrevistas solicitávamos que os docentes levassem os programas nos quais tivemos acesso a oito, pelo fato de um dos sujeitos da pesquisa ter deixado de disponibilizar o documento informando que assumira a disciplina há pouco tempo e que estava providenciando a organização do programa, solicitamos o envio posteriormente, mas não obtivemos retorno.

A análise dos programas de disciplinas proporcionou a confirmação de dados que havíamos constatado nos projetos dos cursos, corroborando que os sete PPC dos cursos de Pedagogia da UECE apresentam propostas formativas diferenciadas em todos os âmbitos, nos quais podemos citar os ementários, especificamente das disciplinas de Didática e Avaliação. Verificamos carga horária diferente entre os componentes curriculares com a mesma nomenclatura, no caso a disciplina de Didática, conforme localizado em um (01) PPC e nos outros seis (06) projetos, intitulada Didática Geral. Em um dos cursos é ofertada no terceiro semestre, em três projetos ocorre no quarto e em outro, no sexto; o referido componente curricular com carga horária diferente em quatro (04) projetos com 68 horas/aulas e quatro créditos e em três (03) PPC com 102 horas/aulas e seis créditos. As disciplinas de Avaliação apontam nomenclaturas diferentes em Avaliação da Aprendizagem e Educacional, sendo essa segunda denominação escolhida pôr no ementário referenciar avaliação da aprendizagem. Apesar da nomenclatura diferenciada, as três disciplinas apresentam 68 horas/aulas e quatro créditos.

Conforme aclaramos anteriormente, a disciplina Didática foi descrita nos PPC com nomenclatura e cargas horárias diferentes. Assim, descrevemos os achados acerca da avaliação do ensino e aprendizagem contidos nos programas das disciplinas disponibilizadas pelos docentes a partir da especificidade de cada componente curricular.

O programa da disciplina de Didática com duração de 68 horas/aulas foi disponibilizado no formato impresso em que a ementa foi retirada do PPC do Curso sem objetivos destinados à avaliação do ensino aprendizagem apresentando a temática na terceira unidade aliada ao planejamento, nas referências foram citados dois livros referentes ao tema. No mesmo curso de Pedagogia a disciplina Avaliação Educacional também com 68 horas/aulas compôs nossa investigação, uma vez que, no ementário foi contemplada a avaliação do ensino e aprendizagem sendo evidenciada nos objetivos da disciplina e destinando uma unidade para estudo desse tema sem indicações bibliográficas ou documentais do referido objeto na bibliografia descrita no programa.

Dentre os quatro programas das disciplinas de Didática Geral que tivemos acesso, recebemos um de 68 horas/aulas referentes a quatro créditos do curso que de acordo com a descrição do programa anterior atendeu ao ementário descrito no PPC, sem destinar nenhum objetivo com foco na avaliação da aprendizagem, pautando os estudos acerca da avaliação na segunda unidade com indicação de dois livros sobre avaliação do ensino e aprendizagem na bibliografia básica.

Os outros três programas das disciplinas de Didática Geral destinaram-se as disciplinas de Didática Geral com carga horária de 102 horas/aulas perfazendo seis créditos da matriz curricular, nos quais apresentaram o ementário da disciplina de acordo com o descrito no Projeto Pedagógico de cada curso. O primeiro programa da disciplina com essa carga horária enfocou em um dos seis objetivos específicos a avaliação da aprendizagem aliada ao planejamento do trabalho pedagógico, bem como o estudo do conteúdo foi pautado na segunda unidade e na bibliografia constavam indi- 
cações de um livro acerca da avaliação da aprendizagem. Em outro programa com a mesma carga horária avaliação da aprendizagem foi contemplada na terceira unidade apesar do documento sinalizar quatro unidades, mas constarem especificações de três. Nas indicações bibliográficas complementares foi citado um livro sobre avaliação da aprendizagem. No programa de disciplina concedido pelo docente do curso em que o PPC estava sendo aprovado pelo Conselho de Educação constava um ementário que foi pesquisado de projetos pedagógicos de outros cursos sem destinar objetivos pautados na avaliação e constando indicações no conteúdo programático da disciplina relacionando com o planejamento e na bibliografia, indicações de obras sobre avaliação foram inexistentes.

Dos sete cursos pesquisados, um ofertava a disciplina de Avaliação da Aprendizagem, sendo disciplina obrigatória e tendo como pré-requisito a disciplina de Didática Geral. Os estudantes do curso de Pedagogia cursavam-na no oitavo semestre atendendo a ementa do projeto de curso e destinando objetivos, conteúdos programáticos e referências ao tema de estudo do componente curricular nomeado de avaliação da aprendizagem.

Nos aspectos referentes ao planejamento avaliativo das disciplinas, os interlocutores entrevistados evidenciaram, em algumas circunstâncias, o planejamento da disciplina como sendo o avaliativo aliando aos aspectos descritos nos Projeto Pedagógico do Curso (PPC), principalmente aos ementários. Também localizamos que três depoentes deixaram de relevar os aspectos do planejamento da avaliação, um (01) se deteve em esboçar sua preocupação com avaliação somativa, revelando a necessidade de diagnóstico das dificuldades dos estudantes por parte do docente, tendo como ponto de partida as informações diagnósticas para implementação de ações de formação.

Em outro depoimento o docente 02 revelou que tanto o planejamento da disciplina como o da avaliação era realizado no primeiro dia de aula, definido com os estudantes, destacando a participação dos discentes no planejamento avaliativo da disciplina como oportunizada o exercício de autonomia, na qual o docente primava pela avaliação formativa e processual realizando a coleta sistemática de informações acerca da aprendizagem. Arredondo e Diago (2009, p. 61) argumentam que a avaliação processual «permite tomar decisões de melhora em andamento, em benefício dos protagonistas: alunos e professores». As informações constantes concedidas pela avaliação processual auxiliam na análise do planejamento demonstrando os resultados das ações previas e oportunizando o redimensionamento das ações em processo. Os aspectos descritos pelo professor 05 coadunam com a descrição do segundo entrevistado ao destacar os aspectos processuais da avaliação, o redimensionamento de ações no decorrer da disciplina e a participação dos estudantes, solicitando modificações na utilização dos instrumentos avaliativos, no caso a prova escrita.

Ao indagarmos a respeito do planejamento avaliativo das disciplinas, detectamos nexos entre o planejamento avaliativo das disciplinas descrito por cinco (05) docentes aos aspectos descritos no PPC nos quais os entrevistados mencionaram os ementários constituintes dos programas das disciplinas.

Cientes da necessidade dos docentes atentarem para o fato de que teoria e prática são elementos distintos, porém inseparáveis na organização do projeto formativo, evidencia-se a concepção de práxis (de prática refletida), de atividades teórico-práticas que têm, de um lado a ação, ou seja, a prática que subsidia o pensamento para a construção de ideias e formas diversas para as intervenções na realidade educacional, e, de outro, a teoria representada por um conjunto de ideias, sistematizado a partir da prática pedagógica. O projeto pedagógico auxilia no processo avaliativo, uma vez que, destaca o alinhamento da teoria e da prática, ou melhor, da práxis. Assim, descobrimos a vinculação do planejamento da avaliação com os PPC de acordo com as explanações dos entrevistados.

Posterior às revelações acerca do planejamento avaliativo e vinculações com os projetos pedagógicos seguimos nossa trajetória cartográfica buscando compreender a disseminação das práticas de avaliação nas licenciaturas em Pedagogia recolhendo informações sobre os modelos avaliativos utilizados pelos professores nas disciplinas de Didática, Avaliação da Aprendizagem e Educacional. Antes de adentramos nas revelações dos entrevistados é importante apresentar o conceito de modelos de avaliação organizado por Bonniol e Vial:

Na educação, a palavra modelo é usada geralmente para designar uma formalização, exemplar: a partir de uma situação estudada, atualizam-se as invariantes dessa situação, as quais passam a ser consideradas princípios gerais que permitem reconhecer ou preconizar outras 
situações do mesmo tipo de problemas. Fala-se então da modelação de uma situação. Essa acepção da palavra modelo, proveniente do estruturalismo, significa exibição de uma estrutura, de uma rede de elementos ligados por relações que são estáveis e que produzem uma função, realizando uma transformação: um conjunto regulamentado de encadeamentos [...]. (Bonniol \& Vial, 2001, p. 11)

Os modelos de avaliação servem de dimensões norteadoras do professor no tocante a avaliação, na perspectiva de oportunizar a percepção das relações existentes no processo de ensino-aprendizagem ficando a critério do docente, selecionar o modelo que proporcionará o reconhecimento das aprendizagens e dificuldades, evidenciando a tomada de decisões auxiliando na adoção de prática formativas e avaliativas.

Ao direcionarmos a pauta das entrevistas para os modelos avaliativos descobrimos que os oito entrevistados desconheciam esse aspecto da avaliação e mencionaram os tipos de avaliação, ora se referindo ao diagnóstico, em outras entrevistas a avaliação formativa, bem como a avaliação somativa que utilizavam no processo formativo. Nos aspectos documentais da disciplina, ou seja, nos programas analisados, mapeamos que em três foram destacadas as características processuais da avaliação, nos demais foram evidenciados os instrumentos e os aspectos criteriais e as indicações da instituição sobre o rendimento dos discentes.

Ao perguntarmos sobre o modelo de avaliação escolhido pelo professor 03 localizamos a ênfase para a criação de instrumento e atenção aos aspectos que surgem no decorrer das aulas e servem para avaliação. Outro docente mencionou a prática como imitação dos modelos revelando o espelhamento nas práticas de seus professores e na proposta de formação que vivenciou se detendo a avaliação classificatória de quantificação das aprendizagens pautada no rendimento e no erro, ou seja, na nota alcançada nos instrumentos avaliativos. A revelação do professor evidenciou autores que desenvolvem estudos na área de avaliação e que constavam no plano de disciplina apresentado pelo interlocutor com foco na avaliação formativa servindo de estratégia para direcionar o processo de ensino tendo por finalidade adquirir informações da aprendizagem ao longo da disciplina. Esse tipo de avaliação possibilita ao docente modificar e reorientar a condução da disciplina.

Nos depoimentos dos docentes 05, 06, 07 e 08 localizamos a inexistência de adoção de modelo de avaliação e encontramos considerações acerca da avaliação diagnóstica realizada nos primeiros encontros da disciplina para sondar o perfil da turma, em que encontramos uma peculiaridade sobre a atuação profissional dos discentes do curso de Pedagogia em um dos cursos da IES que constituíram o saber da experiência ainda como estudantes da licenciatura.

A partir dos dados da pesquisa acreditamos que avaliação precisa servir e auxiliar a todos os envolvidos no processo de formação inicial acadêmica, ou seja, coordenadores, professores e estudantes. Avaliação precisa perpassar todo o ensino, constituindo um processo de retroalimentação, ou seja, possibilitando o redimensionamento das ações a fim de re/orientá-las em direção a finalidade desejada que é destinando-se à aprendizagem dos estudantes. Por meio da avaliação constatamos os progressos, as dificuldades e reorientamos o trabalho formativo no Ensino Superior e nos cursos de licenciatura que formam os professores que atuarão na Educação Básica evitando ficar restrita a verificação do rendimento escolar.

\section{Considerações finais}

Nessa direção consideramos que a análise documental, bibliográfica e as entrevistas realizadas na pesquisa e explicitadas nesse escrito são fundamentais para orientar as práticas formativas dos professores dos cursos de graduação e o trabalho de gestão dos coordenadores, bem como, os projetos de formação nas Universidades. Vale evidenciar que existe uma continuidade desta pesquisa, buscando identificar as dimensões da avaliação do ensino e aprendizagem disseminada tanto nos cursos de Pedagogia como em outros cursos de formação docente.

Depois de localizarmos ausência dos modelos avaliativos, detectamos que nas práticas de avaliação disseminadas nos cursos investigados eram utilizados três tipos de avaliação: avaliação diagnóstica como intuito de sondagem dos conhecimentos prévios para apreensão de outros conteúdos; a formativa, que orientava a (re)organização do trabalho docente e a somativa, expressa como dificuldade por alguns interlocutores pela quantificação de notas, servindo para o julgamento de valor pautado nos níveis de aproveitamento expressos ao final da unidade, semestre ou componente 
curricular. Vale lembrar que, cabe ao docente compreender que avaliação do tipo somativa revela informações que auxiliam no processo de tomada de decisão docente.

$\mathrm{Na}$ descrição encetada acerca das práticas avaliativas no processo de ensino-aprendizagem nos Cursos de Pedagogia, no que concerne ao planejamento avaliativo, alguns professores aclararam inexistência do planejamento na área de avaliação, outros confundiram com o planejamento da disciplina buscando alinhar aos aspectos da avaliação descritos nos PPC das licenciaturas. É válido evidenciar que o planejamento da avaliação auxilia o docente no desenvolvimento das ações de formação propostas no decorrer da disciplina, destinando-se à obtenção de informações, ajudando na formulação dos juízos de valor e, principalmente, na tomada de decisões, subsidiando o ensino, as estratégias metodológicas utilizadas pelo professor na perspectiva de sanar as dificuldades dos estudantes reveladas na formação.

As práticas avaliativas apresentaram necessidade de planejamento avaliativo e acompanhamento processual e, principalmente de tomada de decisões que escolham estratégias que auxiliem na (re)definição do ensino e contribuam para as aprendizagens. Acreditamos que essas dificuldades vinculam-se a desvalorização dos aspectos didáticos na formação docente, e de modo específico na formação dos pedagogos, as generalizações indicando ora a docência e ora exigindo formação para as atividades educacionais técnicas. Localizamos ausências de indicações documentais acerca da avaliação nos aspectos regimental e de modo sucinto no PPC dos cursos. Conhecer o desconhecido é um desafio a ser vencido pelo homem, principalmente na docência, requerendo (re)significar e modificar as experiências, evitando a estagnação do caráter experiencial, partindo para o estudo, análise, reflexão buscando compreender os fenômenos vivenciados na profissão docente e suas relações com o contexto educacional, político e social.

Destacamos que a proficuidade da avaliação necessita vir a ser incorporada no trabalho docente como uma prática contínua. Ao adotar uma perspectiva de continuidade, a avaliação permeará o trabalho docente ofertando possibilidades de diagnósticos, superação de dificuldades e correção de falhas, incentivando os estudantes a dedicação aos estudos, por conseguinte atingindo a sua função precípua de constituição de aprendizagens.

As práticas de avaliação no ensino-aprendizagem pautadas no planejamento e nos modelos avaliativos no âmbito da educação superior nos levaram a perceber a relevância e necessidade de aquisição do conhecimento em avaliação pelos docentes, requerendo ser pensada de forma articulada com a concepção de currículo, uma vez que nela se expressa, sobretudo as escolhas dos conteúdos, as definições emanadas do planejamento, a elucidação dos modelos, a sistematização dos instrumentos e critérios com escopo no trabalho do professor e na aprendizagem dos discentes.

Um dos desafios na investigação refere-se à falta de acesso a alguns documentos, como ao Projeto Pedagógico de um dos cursos escolhidos, pois segundo informações da gestão o documento foi extraviado. Motivo pelo qual se torna imprescindível à adoção de políticas de guarda e manutenção dos acervos nas instituições, seja na forma física e digital.

Desejamos que a pesquisa inquiete a comunidade acadêmica norteando outras trilhas no desenvolvimento de investigações que busquem compreender as práticas avaliativas disseminadas na educação básica ou superior, no intento de analisar, propor melhorias para educação brasileira, e em outros países, em diferentes nível e modalidades. Além disso, que os achados sirvam de norteadores para as políticas educacionais, auxiliando gestores, docentes e licenciandos.

\section{Referencias}

Arredondo, S. C., \& Diago, J. (2009). Avaliação educacional e promoção escolar (S. M. Dolinsky, Trad.). Curitiba: Ibpex; São Paulo: Unesp.

Berbel, N. A. N. (2001) Avaliação do Ensino Superior. Londrina: Ed. UEL.

Bonniol, J. J., \& Vial, M. (2001) Modelos de Avaliação. Porto Alegre: Artmed.

Luckesi, C. C. (2011). Avaliação da aprendizagem escolar: componente do ato pedagógico. São Paulo: Cortez.

Oliveira, E. G., \& Damis, O. T. (2011). Planejamento: processo de organização e de sistematização da prática de didática na formação de professores. In: A. M. Longarezi, \& R. V. Punetes (Orgs.). Panorama da Didática. Ensino, prática e pesquisa. São Paulo: Papirus.

Prado, G. V. T., \& Cunha, R. B. (Orgs.). (2007). Percursos de Autoria-exercícios de pesquisa. Campinas, SP: Alínea.

Resolução CNE/CP n ${ }^{\circ}$ 02, de $1^{\circ}$ de julho de 2015. Define as Diretrizes Curriculares Nacionais para 
a formação inicial em nível superior (curso de licenciatura, cursos de formação pedagógica para graduados e curso de segunda licenciatura) e para formação continuada. Recuperado de http://portal.mec.gov.br/docman/agosto-2017-pdf/70431-res-cne-cp-002-03072015-pdf/file

Roldão, M. C., \& Ferro, N. (2015). O que é avaliar? Reconstrução das Práticas e Conceções de Avaliação. Estudos em Avaliação Educacional, 26(63), pp. 570-594. doi: https://doi.org/10.18222/eae.v26i63.3671

Silva, M. L., Neta., \& Magalhães, A. G., Jr. (2017). Práticas avaliativas na formação docente: teoria e prática. Horizontes, 35(2), pp. 38-48. doi: https://doi.org/10.24933/horizontes.v35i2.328

SILVA, M. L. Neta. O conhecimento avaliativo dos docentes dos cursos de pedagogia: cartografia dos saberes, práticas e formação. Tese (Doutorado em Educação) - Programa de Pós-Graduação em Educação, Universidade Estadual do Ceará, Fortaleza, 2018.

Sordi, M. R. L., \& Ludke, M. (2009). Da avaliação da aprendizagem à avaliação institucional: aprendizagens necessárias. Avaliação, 14(2), pp. 253-266. doi: https://doi.org/10.1590/S1414$\underline{40772009000200005}$ 